\title{
Metaphor and Elaboration in Context
}

\author{
Paul H. Thibodeau ${ }^{1}$ \& Stephen J. Flusberg ${ }^{2}$
}

${ }^{1}$ Oberlin College, Department of Psychology (paul.thibodeau@oberlin.edu)

${ }^{2}$ Purchase College, SUNY, Department of Psychology (stephen.flusberg@purchase.edu)

This manuscript is forthcoming in the book Dynamism in Metaphor and Beyond. To be cited as:

Thibodeau, P.H., \& Flusberg, S.J. (In press). Metaphor and elaboration in context. In H.L.

Colston, T. Matlock, and G.J. Steen (Eds.), Dynamism in Metaphor and Beyond. John Benjamins Publishing. 


\section{Introduction}

Consider the following classic — if uninspired — story:

John went to a restaurant.

He ordered lasagna.

Later, he paid and left.

Though the vignette never explicitly mentions what or whether John ate, whether he talked to a server, or why he paid, people readily infer these details (Bower, Black, \& Turner, 1979). John probably ate lasagna (since that's what he ordered), he probably ordered the lasagna from a server, and he probably paid because food at restaurants costs money. John's culinary adventure illustrates the elaboration problem in the study of discourse comprehension. Narratives "are usually elliptical and abbreviated, suggesting far more than they say explicitly" (p. 177-178; Bower, Black, \& Turner, 1979. Emphasis added). People, however, usually understand them without much trouble.

The ease with which we comprehend narratives in context reflects the fact that we integrate linguistic input with prior knowledge (Graesser, Millis, \& Zwaan, 1997). This type of prior knowledge — often called scripts, schemas, or frames — is relatively abstract and includes information about objects, agents, and causal relationships that are typical in the domain in question (Gentner, 1983; Kintsch, \& van Dijk, 1978; Mandler, 2014; Minsky, 1975; Rumelhart, 1975; Schank \& Abelson, 1977). An important property of schematic knowledge is that it is shared among members of a linguistic community; it comprises the common ground which 
enables speakers to be efficient and relevant when they talk (Clark, 1996; Grice, 1975; Sperber \& Wilson, 1987). For example, when a group of college students was asked to "write a list of actions describing what people generally do when they [attend a lecture, visit a doctor, shop at a grocery store, or get ready for school]," there was widespread agreement about the "basic actions" that constituted each event (Bower, Black \& Turner, 1979). You won't be surprised to hear that eating at a restaurant typically involves "being seated," "looking at a menu," “ordering," "eating," "paying," and "leaving" (in that order). People are faster to process descriptions of events that conform to these canonical story scripts (e.g., Bower, Black \& Turner, 1979), and they are more likely to remember experiences in a way that is consistent with familiar cultural schemas (e.g., Bartlett, 1932).

That said, there are many important domains-like criminal justice and politics—-that lack a singular well-defined schema, either because the subject is too complex or because it affords many competing conceptualizations, or both. In such cases, speakers often rely on figurative descriptions that invite a comparison between the topic of conversation and a less complex domain. ${ }^{1}$ When we talk about a "crime epidemic" or a "gridlocked political system," for example, we are speaking metaphorically, borrowing language from one domain to describe another. Lakoff and Johnson (1980) showed that systems of conventional metaphors like these suffuse natural language: Crime not only spreads like a "viral epidemic, plaguing cities and infecting communities," it is a problem that politicians and law enforcement officers seek to “diagnose and treat." In this way, conventional metaphors draw on elaborate mappings between

\footnotetext{
${ }^{1}$ Indeed, recent work has found an especially high prevalence of metaphor in academic articles (17\% metaphorical), compared to news stories (15\%), fiction (11\%), and conversation (7\%) - possibly because of the abstractness and complexity of academic domains of study (Gibbs, 2015; Steen et al., 2010). In one study, for example, researchers found that $29 \%$ of words in academic discourse on music was metaphor-related (Pérez-Sobrino \& Julich, 2014).
} 
disparate domains like CRIME IS A VIRUS and GOVERNMENT IS A VEHICLE. ${ }^{2}$ Importantly, the source domains in these types of metaphors (VIRUS, VEHICLE) tend to be associated with familiar and clearly delineated conceptual schemas (Lakoff \& Johnson, 1980, 1999; Flusberg, Matlock, \& Thibodeau, 2018).

Lakoff and Johnson (1980) famously argued that the prevalence and systematicity of metaphor in language shows that "the human conceptual system is metaphorically structured and defined" (p. 6). Consequently, the mappings they document have been called conceptual metaphors, and their broader theoretical claim about the role of metaphor in mental representation has been called conceptual metaphor theory (CMT). According to CMT, we don't just speak metaphorically, we think metaphorically. These claims challenged longstanding assumptions about the nature of language and cognition (Gibbs, 1994) and inspired heated debates about the representations and processes involved in metaphor comprehension (e.g., Gibbs, 1996, 2011; McGlone, 2007, 2011; Murphy, 1996, 1997; Pinker, 2007; for an overview of these Metaphor Wars, see Gibbs, 2017). More recently, CMT has motivated many researchers to investigate the power of metaphor to shape how we talk, think, and reason about the topics we care most about.

In this chapter, we situate recent studies of metaphor comprehension and metaphor framing under broader theories of discourse processing, drawing out the connections between classic work on narratives, schemas, and elaboration and contemporary research on metaphor. This approach emphasizes that language is used to solve coordination problems in a socialpragmatic context (Clark, 1996; Steen, 2008). That is, listeners actively use language in combination with other sources of information (prior knowledge, gesture, and so on) to construct

\footnotetext{
${ }^{2}$ See the MetaNet Metaphor Wiki for a catalog of conceptual metaphors (https://metaphor.icsi.berkeley.edu/pub/en/).
} 
mental models in working memory that they can use to make decisions and act in a dynamic social world (Boroditsky, 2000; Gibbs, 1994; Graesser, Millis, \& Zwaan, 1997). Just as reading a sentence like "John went to a restaurant" calls to mind general knowledge about restaurantswhich helps the listener build a richer "online" representation of the event than is communicated in the linguistic input alone — so too does reading about a "crime epidemic" call to mind salient schematic knowledge associated with the source domain (VIRUS), which helps the listener build a richer representation of the target domain (CRIME) that can drive decision-making.

Grounding recent research on metaphor in well-established empirical work on language processing does three things: (1) it exposes certain limitations associated with alternative accounts of metaphor processing, (2) it helps make sense of a broad range of findings on the role of metaphor in persuasive communications and decision-making, and (3) it points to several promising avenues for future research by drawing attention to what a strict "schematic elaboration" model of metaphor processing leaves out or ignores. Exploring these consequences, we hope, helps nudge people towards a more dynamical view of metaphor in cognition and communication (cf. Gibbs \& Colston, 2012).

\section{Metaphoric Mappings in Language \& Thought}

Consider the following story of a romantic relationship (which, if we're being honest, is only slightly more interesting than John's trip to café Lasagna):

Bill and Lauren have been together for three years.

There have been potholes along the way and now they are at a junction.

The relationship has stalled. 
People readily understand this story to mean that Bill and Lauren are experiencing challenges in their relationship, although this point is never made with explicit literal language, or even conventional metaphoric language. Instead, it is conveyed through novel instances of the conceptual metaphor RELATIONSHIPS ARE JOURNEYS. In this case, the relationship is characterized as similar to a road trip in a car. The time that Bill and Lauren have been together is mapped onto what people know about roads, which can be smooth or bumpy or full of holes. The current status of the relationship is like a car that has stopped at an intersection. The relationship might be able to continue into the future (moving forward), but it might not. Getting the relationship going again will take some effort.

Cognitive scientists generally agree that making meaning from novel metaphors involves a "mapping" process, whereby features and relations from the source domain are projected or mapped onto the structure of the target domain via a process of analogy-making (e.g., Bowdle \& Gentner, 2005; Keysar, Shen, Glucksberg, \& Horton, 2000). We have illustrated this process in the previous paragraph, though it may unfold spontaneously and unconsciously in the course of everyday communication. There is disagreement, however, over whether conventional metaphoric expressions activate conceptual mappings in the moment: "conceptual mappings are not routinely used when people comprehend conventional expressions" (p. 579, Keysar et al., 2000).

This points to a critical limitation of early formulations of CMT from a cognitive psychological perspective: its reliance on linguistic evidence alone in making psychological claims. On the one hand, conventional metaphors in language could reflect the metaphorical nature of the human conceptual system. Reading a phrase like "crime epidemic" might instantiate 
a conceptual mapping that leverages what people know about virus problems to structure their thinking about crime. This could be why conventional metaphors in natural language are prevalent and systematic. On the other hand, people may simply process most conventional metaphors in language idiomatically. Phrases like "kick the bucket" and "red herring" are idiomatic expressions with established lexicalized meanings in English that can be understood directly (i.e. without activating a conceptual mapping). That is, people just seem to know that "kick the bucket" means "to die" and "red herring" means "a misleading fact." On this alternative view, the prevalence and systematicity of conventional metaphor in language reflects general patterns of semantic change over time, not how individual speakers of a language process conventional metaphors or use them to think (e.g., Murphy, 1996; Pinker, 2006; but see Gibbs, 1996).

The tools developed by cognitive psychologists to study narrative comprehension are well suited to testing the divergent predictions of these accounts. One approach has been to compare how quickly people read novel metaphoric target sentences in different contexts. Bill and Lauren's tragic love story contains novel instances of the conceptual mapping RELATIONSHIPS ARE JOURNEYS. A similar meaning can be expressed with conventional metaphors that appeal to the same conceptual mapping or with non-metaphorical language (see Table 1).

Table 1. Example stimulus from Thibodeau and Durgin (2008). Italics added to highlight instances of metaphor.

\begin{tabular}{|l|l|}
\hline $\begin{array}{l}\text { Novel } \\
\text { metaphorical }\end{array}$ & $\begin{array}{l}\text { Bill and Lauren have been together for three years. There have been } \\
\text { potholes along the way and now they are at a junction. Their } \\
\text { relationship is stalled. }\end{array}$ \\
\hline $\begin{array}{l}\text { Conventional } \\
\text { metaphorical }\end{array}$ & $\begin{array}{l}\text { Bill and Lauren have been together for three years. It has been a long, } \\
\text { bumpy road and now they are at a crossroad. Their relationship isn't } \\
\text { going anywhere. }\end{array}$ \\
\hline
\end{tabular}




\begin{tabular}{|l|l|}
\hline Non-metaphorical & $\begin{array}{l}\text { Bill and Lauren have been together for three years. They have had } \\
\text { problems in their relationship and now they have to make a choice. } \\
\text { Their relationship isn't good. }\end{array}$ \\
\hline TARGET & They are in serious need of a jumpstart. \\
\hline
\end{tabular}

In one study, participants read one of three versions of a scenario, followed by a target sentence (Thibodeau \& Durgin, 2008). The scenario was either presented with novel metaphorical language, conventional metaphorical language, or non-metaphorical language. After reading the scenario, participants were timed reading a target sentence like, "They are in serious need of a jumpstart." In every case, the target sentence extended the conceptual mapping that was instantiated by the novel and conventional metaphorical language. It was designed so that people could still understand its meaning in the context of non-metaphorical language, but it would take some work (i.e., a mapping).

As expected, people took longer to read the target sentence after reading the nonmetaphorical description of the story relative to the novel metaphorical description of the story. This is because participants reading the novel metaphorical description would have already generated the mapping between journeys and relationships before reading the schematically congruent target sentence. The critical condition examined how long it took people to read the target sentence in the conventional metaphorical condition. If people read the target sentence quickly in that context, it would suggest that we activate conceptual mappings for conventional metaphoric expressions, not just novel ones. If they read it slowly, it would suggest that conventional metaphors are processed more like literal language. The results showed that people read the target sentence as quickly in the conventional metaphorical condition as in the novel metaphorical condition, providing evidence that conventional metaphors call to mind more elaborate knowledge about relationships between the source and target domains. 
One alternative explanation for this finding is that reading metaphorical language - be it novel or conventional—caused people adopt a particular "cognitive style" that facilitated subsequent processing of the metaphoric target sentence. Maybe reading one metaphor facilitates processing of another, irrespective of their conceptual mappings, because it leads people to think more creatively or abstractly in general. To test this explanation, a follow-up experiment contrasted how quickly people read a novel metaphoric target sentence after reading related or unrelated conceptual metaphors. For example, the story below appeals to the conceptual metaphor RELATIONSHIPS ARE PATIENTS but expresses a similar meaning as the examples above.

Bill and Lauren have been together for three years.

Their relationship has been unhealthy before, but now it is nearly dead.

The results of this experiment supported the view that conventional metaphors activate conceptual mappings, rather than a particular cognitive style. Participants understood matched target sentences (i.e., those where initial and target sentences drew on the same conceptual metaphor) faster than mixed metaphor target sentences. For example, the target sentence "They'd better find some medicine fast" was understood more quickly when the relationship had been described as a metaphorical PATIENT, whereas the target sentence "They need a better navigation system" was understood faster when the relationship had been described as a metaphorical JOURNEY. The amount of time it took participants to read the target sentences after a nonmetaphorical description of the scenario was similar to how long it took them to read the target sentence in the mixed metaphor condition. Together, these studies suggest that understanding metaphors in language — conventional or novel—activates elaborate conceptual schemas (see 
also Gibbs, 1984; Nayak \& Gibbs, 1990). That said, one alternative possibility is that this type of facilitation effect is simply the result of lexical priming (e.g., McGlone, 2011). We explore this question later in the chapter.

\section{Metaphor Framing in Decision-Making}

The overarching claim of this chapter is that metaphors help people structure and elaborate on mental representations of the domains that they're used to describe. If metaphors play such a role, then we should be able to measure these effects in decision-making tasks. For example, framing a problem with different metaphors should lead people to draw different inferences about how to solve it. This possibility has been tested in a variety of domains that are fundamental to a well-functioning society and our everyday life, revealing effects of metaphors on reasoning about cancer, loving relationships, educational goals, immigration, global warming, federal budgets, law enforcement, and a host of other issues (e.g., Elmore \& Luna-Lucero, 2016; Flusberg, Lauria, Balko \& Thibodeau, 2020; Flusberg, Matlock, \& Thibodeau, 2017; Hauser \& Schwarz, 2015; Landau, Sullivan, \& Greenberg, 2009; Robins \& Mayer, 2000; Thibodeau, 2016; Thibodeau, Crow, \& Flusberg, 2018; Thibodeau \& Flusberg, 2017).

In a typical metaphor framing study, participants first read a brief paragraph about a complex topic containing one of two different metaphors ${ }^{3}$ and are then asked to make a judgment or decision about the target issue. The metaphors are intended to call to mind distinct conceptual schemas that highlight unique aspects of the target domain and generate different entailments for how to deal with the problem. For example, framing CRIME as a VIRUS leads people to think

\footnotetext{
${ }^{3}$ Sometimes a non-metaphorical control condition is included as well (e.g., Flusberg, Matlock, \& Thibodeau, 2017; Steen, Reijnierse, \& Burgers, 2014), but see Thibodeau (2017) and Thibodeau \& Boroditsky (2015) for limitations associated with this approach.
} 
about the spread of crime through a city, the conditions that facilitate its transmission, and how to improve these conditions. Framing CRIME as a BEAST leads people to think about the individual violent actions of criminals and the role of law enforcement in capturing and caging criminals. Several studies have shown that, compared to framing CRIME as a BEAST, framing CRIME as a VIRUS makes people more likely to endorse crime-reduction strategies that focus on social reform than on enforcement-based strategies (and vice versa; Christmann \& Göhring, 2016; Thibodeau \& Boroditsky, 2011, 2013). That is, people tend to prefer solutions to the crime problem that are conceptually congruent with the metaphorical source domain schema.

In line with research on the role of schematic knowledge in narrative language processing (e.g., Bransford \& Johnson, 1972), metaphors seem to be most effective when they are presented early in a stream of processing (Read, Cesa, Jones, \& Collins, 1990; Reijnierse, Burgers, Krenmayr, \& Steen, 2015; Sopory \& Dillard, 2002; Thibodeau, 2017). For example, reading about a crime problem that starts with a metaphorical comparison to a virus or beast problem influences how people suggest solving it, but reading about a crime problem that ends with one of these metaphorical comparisons does not (Thibodeau \& Boroditsky, 2011). Because language processing unfolds dynamically over time, a frame that is presented early (metaphorical or otherwise) is in a position to activate a conceptual schema that can scaffold how people interpret and make sense of downstream linguistic input (which may be ambiguous or open to multiple construals; Thibodeau \& Boroditsky, 2011; Tversky \& Kahneman, 1981). Conversely, a frame that is presented later in the linguistic stream may be relatively ineffective because people will have already constructed a particular mental representation of the topic at hand, which could be difficult to shift in the moment. 
In addition, people are more likely to endorse a course of action when it is described in a way that makes it more compatible with the metaphorical frame (Keefer, Landau, Sullivan, \& Rothschild, 2014; Hauser \& Schwarz, 2015; Landau, Keefer, \& Swanson, 2017; Thibodeau, 2016). For instance, when social reforms are framed as a way to "treat" a metaphorical virus and enforcement tactics are framed as a way to "fight" a metaphorical beast, people are especially likely to suggest the metaphor-consistent response to crime (Flusberg et al., 2020; Thibodeau, 2016). That said, people are often unaware of a metaphor's influence in metaphor framing studies. When asked to explain their decision about a metaphorically framed problem, participants rarely seem to think the metaphor was a significant factor. Indeed, many cannot even remember what metaphor they read even though the results of the study suggest that it influenced how they thought about the issue (Thibodeau, 2017; Thibodeau \& Boroditsky, 2013; but see Flusberg et al., 2020).

Finally, recent work on metaphor framing has begun exploring how different types of metaphors affect decision making (e.g., Gentner \& Asmuth, 2017; Thibodeau, Winneg, Frantz, \& Flusberg, 2016; Vendetti, Wu, \& Holyoak, 2014). One way that metaphors vary is in the degree to which they draw on "deep" relational structure - as opposed to more superficial features - of the source domain (Gentner, 1983). For example, the conceptual metaphor CRIME IS A VIRUS seems to call on a system of knowledge about the causes and consequences of viral infections. On the other hand, "The sun is an orange" is more of a feature-based metaphor, drawing attention to the shape and color of the objects (i.e., both are round and orange). One study found that reading a series of more systemic metaphors induces a "systems thinking" mindset, in which people are more attentive to structural forces of domains (Thibodeau, Winneg, Frantz, \& Flusberg, 2016). This work highlights the fact that metaphors vary with respect to the 
schematic elaboration they elicit, which may have implications for the efficacy of metaphor framing in different contexts.

\section{Are Metaphors Just Lexical Primes?}

So far, we have been using the terms "schematic elaboration" and "mapping" to explain how people process and use metaphors - an account which dovetails with classic work on narrative comprehension. But there is a simpler, alternative account of the findings we have described that says metaphors are simply lexical primes that activate associated words and concepts. On this view, reading a conventional metaphor doesn't generate an elaborate mapping across domains; rather it activates words that are semantically associated with the metaphor, which can then be processed more quickly (e.g., McGlone, 2011). This could explain why people are faster to read target sentences that are preceded by congruent conventional metaphorical descriptions in language processing tasks and why they select response options that contain language associated with a metaphorical frame in decision-making tasks.

One way that researchers have attempted to adjudicate between these two accounts has been to focus on conceptual metaphors with more nuanced structural mappings. For example, people often talk about TIME as SPACE. However, linguistic analyses suggest that there are at least two coherent mappings between these domains (Clark, 1973; Lakoff \& Johnson, 1980). In one, people agentively move through time like they move through space (ego-moving; e.g., "We're quickly approaching the deadline"). In the other, time moves towards (and past) people like a moving object (time-moving; e.g., "The deadline is quickly approaching"). Experiments have found that people are faster to read a series of spatiotemporal metaphors in which the mapping of time onto space is consistent (ego-moving vs. time-moving) — even when the same spatial 
language (e.g., ahead, before, behind) is used for both types of metaphors, thus controlling for lexical priming (Gentner, Imai, \& Boroditsky, 2002; McGlone \& Harding, 1998).

In the context of metaphorical framing, the results of several studies suggest that metaphor frames do more than simply activate lexical associations (e.g., Hendricks, Demjén, Semino, \& Boroditsky, 2018; Thibodeau \& Boroditsky, 2011; Thibodeau, Crow, \& Flusberg, 2018). For example, reading a metaphorical statement that compares police officers to "warriors" or "guardians" predictably affects peoples' attitudes toward law enforcement and the criminal justice system; participants report more favorable attitudes when police officers are metaphorical "guardians of the community" and less favorable attitudes when police officers are metaphorical "warriors of the community." If these results could be explained by lexical priming, then simply exposing people to the word "warrior" or "guardian" (absent a metaphorical comparison to police officers) should have a similar influence on peoples' attitudes. An empirical test of this possibility showed that it doesn't work (Thibodeau, Crow, \& Flusberg, 2017). This supports the view that metaphor framing effects are the result of more nuanced cognitive processes than lexical priming alone.

\section{Interim Summary}

Experimental research on how people process conceptual metaphors in discourse and use them to make decisions paints a nuanced, but dynamic picture of the cognitive representations and processes involved. It suggests that metaphors are special in the way that they leverage what people know about clearly delineated conceptual domains (like viral epidemics and journeys in vehicles) to represent and reason about more complex ones (like crime and politics). This makes 
metaphors particularly useful in advertising, teaching, and science, which all require effectively communicating about new, unfamiliar, complex, and abstract topics.

On the other hand, we have situated this work in the broader literature on discourse processing to highlight some of the underlying similarities between metaphor processing per se and language processing in general (see also Gibbs \& Gerrig, 1989). Processing metaphorical language in context, like literal language, involves more than simply retrieving the lexical entries of individual words or activating semantically related concepts. It requires people to elaborate on what is actually described, drawing on pre-existing schematic knowledge to fill in the gaps, which, in turn, affects how we construe and reason about events.

This perspective highlights a limitation of the view that conventional metaphors are processed idiomatically, like literal language, because it obscures the elaboration problem. It also highlights a limitation of research that focuses on de-contextualized instances of metaphor comprehension like isolated cases of nominal metaphors (e.g., "My job is a jail"; see Glucksberg, 2001). Isolated instances of metaphor in language are somewhat common, but metaphors are typically used more systematically in a wider communicative framework (Gibbs \& Gerrig, 1989; Lakoff \& Johnson, 1980).

\section{What Schematic Elaboration Leaves Out}

In the course of exploring the schematic elaboration account of metaphor we have intentionally sidestepped several important issues about the nature of metaphorical language and cognitive processing. One reason is that, like many classic accounts in cognitive psychology, the schematic elaboration view is somewhat vague. There are open questions about the format of 
schematic knowledge structures and the processes involved in carrying out conceptual mappings. These open questions are opportunities for future research.

For example, there are several competing computational frameworks that invoke distinct cognitive (and neural) mechanisms to explain the conceptual mapping process- though most of them are consistent with schematic elaboration at a certain level of abstraction. Some models propose that "mapping" must be carried out by a dedicated process that identifies correspondences between symbolic (or hybrid) representations of the source and target domains (Doumas, Hummel, \& Sandhofer, 2008; Falkenhainer, Forbus, \& Gentner, 1989; Hummel \& Holyoak, 1997). Other models suggest that "mapping" may be a more emergent phenomenon that is a function of how information is propagated through networks comprised of distributed (and potentially overlapping) conceptual representations (Flusberg, Thibodeau, Sternberg, \& Glick, 2010; Kollias \& McClelland, 2013; Leech, Mareschal, \& Cooper, 2008; Thibodeau, Flusberg, Glick, \& Sternberg, 2013). These two classes of models may be best suited to capturing different types of behavioral findings, which could indicate that a more complex and heterogenous account of metaphorical cognition is needed. On the other hand, none of these models has been used to generate testable predictions about precisely when and why we should expect certain metaphors to shape judgments and decision-making.

A related issue concerns the role of embodied experience in the development and representation of metaphorical concepts ${ }^{4}$. Lakoff and Johnson $(1980 ; 1999)$ pointed out that many of the source domains for conventional metaphors derive from everyday embodied experiences, like moving through space (e.g., "let's move the meeting forward") and sensory

\footnotetext{
${ }^{4}$ We have argued elsewhere that connectionist models that learn the statistical patterns in their input via an errordriven learning process and store information in overlapping, distributed representations may provide a framework for understanding the role of embodied experience in metaphor and thought (Flusberg et al., 2010; see also Feldman, 2008).
} 
perception (e.g., "her alibi smells fishy." See also Gibbs, 1996; Gibbs, Lima, \& Francozo, 2004). This highlights the importance of metaphor as a mechanism for grounding representations of abstract concepts that we cannot experience directly through the senses (e.g., TIME, SUSPICIOUSNESS), and fits with an emerging view that many, if not all conceptual processes are supported by embodied, sensorimotor representations (e.g., Barsalou, 2008; Bergen, 2012; Feldman, 2008; Gibbs, 2005, 2006; Gibbs \& Matlock, 2008; Lakoff \& Johnson, 1999). However, there are still disagreements about what it means for a metaphorical concept to be "embodied" and whether the empirical literature actually supports such a conclusion (e.g., Casasanto \& Gijssels, 2015; Lakens, 2014).

Consider the headline-grabbing "embodied priming" studies that have appeared in recent years, which seem to demonstrate that that subtle sensory experiences can dramatically shift how people think about a metaphorically-linked target domain (for review, see Lee \& Schwartz, 2014; Meier, Schnall, Schwarz, \& Bargh, 2012). For instance, one study found that literally smelling something fishy made people more suspicious and less cooperative in an economic trust game (Lee \& Schwarz, 2012), while another found that people who held a hot (versus cold) cup of coffee evaluated another person as having a (metaphorically) warmer personality (Williams \& Bargh, 2008). Findings like these have been taken as evidence that metaphorical concepts are meaningfully embodied and grounded in sensorimotor representations in the brain (Lee \& Schwartz, 2014; Meier et al., 2012). However, this work has been criticized on both theoretical and empirical grounds (e.g., Lakens, 2014). One the one hand, many of these studies have failed to replicate when subjected to stricter methodological procedures - including the relationship between physical and interpersonal warmth (Chabris et al., 2018). On the other hand, it remains unclear whether priming techniques can even in principle rule out alternative, "non-embodied" 
accounts of metaphoric representation (Casasanto \& Gijssels, 2015). Beyond calling attention to the important distinction between metaphor "framing" (explicitly characterizing the target domain in terms of the source domain) and "priming" (simply activating the source domain of a conceptual metaphor), the schematic elaboration account has little to add to debates over the embodiment of metaphorical concepts, so we leave it to future research to resolve this issue.

One thing we can say about the view of metaphor developed in this chapter is that, like many early models in cognitive psychology, it ignores a critical mental ingredient: emotion. As far back as Aristotle, scholars interested in metaphor and persuasive communication have emphasized that the power of figurative language derives not only from its structural entailments, but also from the emotional impact it has on the listener (see Bowers \& Osborn, 1966; Hitchon, 1997; Johnson \& Taylor, 1981; Reali, Soriano, \& Rodriguez, 2016; Siltanen, 1981; Thibodeau, Crow, \& Flusberg, 2017). Many common metaphorical source domains, like WAR, DISEASE, and BEAST, are associated with high levels of arousal and negative valence, which can elicit feelings of disgust and fear that shape attitudes and decision-making (e.g., Citron \& Goldberg, 2014; Flusberg, Matlock, \& Thibodeau, 2018; Winter, 2019). While the affective component of metaphor processing and metaphor use has received increased attention in recent years, models of metaphor have yet to fully grapple with this issue, and it promises to be a fertile ground for future research (cf. Holyoak \& Stamenkovic, 2018).

\section{Conclusions}

The prevalence and systematicity of metaphor in language raises fundamental questions about the language system, the conceptual system, and the relationship between language and thought. We have focused on the specific question of how people understand conventional 
metaphors in a discourse context. Conventional metaphors often draw from well-established conceptual mappings in language; are these mappings called to mind when people read them? Results of studies that measure how quickly people read metaphoric language and the inferences people make about metaphorically framed dilemmas suggest that they do. Metaphors influence how people elaborate on descriptions of events in language, leveraging what people know about the source domain to structure and color their mental representation of the target domain.

The way that metaphors draw on prior schematic knowledge from one domain to shape how people understand another (semantically unrelated) domain distinguishes it from nonmetaphorical language. But some of the basic processes involved in making meaning from metaphorical language in context, like the activation of prior schematic knowledge to augment mental representations, are similar to those involved in non-metaphorical language processing. Highlighting these similarities and differences, we think, can help researchers develop more comprehensive theories of language processing and knowledge representation as well as paving the way towards fruitful avenues of future research. 


\section{References}

Barsalou, L. W. (2008). Grounded cognition. Annual Review of Psychology, 59, 617-645.

Bartlett, F. C. (1932). Remembering: An experimental and social study. Cambridge: Cambridge University.

Bergen, B. K. (2012). Louder than words: The new science of how the mind makes meaning. New York: Basic Books.

Boroditsky, L. (2000). Metaphoric structuring: Understanding time through spatial metaphors. Cognition, 75(1), 1-28.

Bowdle, B. F., \& Gentner, D. (2005). The career of metaphor. Psychological review, 112(1), 193-216.

Bower, G. H., Black, J. B., \& Turner, T. J. (1979). Scripts in memory for text. Cognitive Psychology, 11(2), 177-220.

Bowers, J. W., \& Osborn, M. M. (1966). Attitudinal effects of selected types of concluding metaphors in persuasive speeches. Communications Monographs, 33(2), 147-155.

Bransford, J. D., \& Johnson, M. K. (1972). Contextual prerequisites for understanding: Some investigations of comprehension and recall. Journal of verbal learning and verbal behavior, 11(6), 717-726.

Casasanto, D., \& Gijssels, T. (2015). What makes a metaphor an embodied metaphor? Linguistics Vanguard, 1(1), 327-337.

Chabris, C. F., Heck, P. R., Mandart, J., Benjamin, D. J., \& Simons, D. J. (2018). No Evidence That Experiencing Physical Warmth Promotes Interpersonal Warmth. Social Psychology

Christmann, U., \& Göhring, A. L. (2016). A German-language replication study analysing the role of figurative speech in reasoning. Scientific data, 3, 160098. 
Citron, F. M., \& Goldberg, A. E. (2014). Metaphorical sentences are more emotionally engaging than their literal counterparts. Journal of Cognitive Neuroscience, 26(11), 2585-2595.

Clark, H.H. (1973) Space, time, semantics, and the child. In Cognitive Development and the Acquisition of Language (Moore, T., ed.), pp. 27-63, Academic Press.

Clark, H.H. (1996). Using Language. Cambridge: Cambridge University Press.

Doumas, L., Hummel, J., \& Sandhofer, C. (2008). A theory of the discovery and predication of relational concepts. Psychological Review, 115, 1-43.

Elmore, K. C., \& Luna-Lucero, M. (2017). Light bulbs or seeds? How metaphors for ideas influence judgments about genius. Social Psychological and Personality Science, 8(2), 200-208.

Falkenhainer, B., Forbus, K. D., \& Gentner, D. (1989). The structure-mapping engine: Algorithm and examples. Artificial Intelligence, 41, 1-63.

Feldman, J. (2008). From molecule to metaphor: A neural theory of language. MIT press

Flusberg, S. J., Lauria, M., Balko, S., \& Thibodeau, P. H. (2020). Effects of Communication Modality and Speaker Identity on Metaphor Framing. Metaphor and Symbol, 1-17.

Flusberg, S. J., Matlock, T., \& Thibodeau, P. H. (2017). Metaphors for the war (or race) against climate change. Environmental Communication, 11(6), 769-783.

Flusberg, S. J., Matlock, T., \& Thibodeau, P. H. (2018). War metaphors in public discourse. Metaphor and Symbol, 33(1), 1-18.

Flusberg, S. J., Thibodeau, P. H., Sternberg, D. A., \& Glick, J. J. (2010). A connectionist approach to embodied conceptual metaphor. Frontiers in Psychology, 1:12.

Gentner, D. (1983). Structure-mapping: A theoretical framework for analogy. Cognitive Science, $7(2), 155-170$. 
Gentner, D., \& Asmuth, J. (2017). Metaphoric extension, relational categories, and abstraction. Language, Cognition and Neuroscience, 1-10.

Gentner, D., Imai, M., \& Boroditsky, L. (2002). As time goes by: Evidence for two systems in processing space $\rightarrow$ time metaphors. Language and cognitive processes, 17(5), 537-565.

Gibbs Jr, R. W. (1984). Literal meaning and psychological theory. Cognitive Science, 8(3), 275304.

Gibbs Jr, R. W. (1994). The poetics of mind: Figurative thought, language, and understanding. Cambridge University Press.

Gibbs Jr, R. W. (1996). Why many concepts are metaphorical. Cognition, 61(3), 309-319.

Gibbs Jr, R. W. (2005). Embodiment and cognitive science. Cambridge University Press.

Gibbs Jr, R. W. (2006). Metaphor interpretation as embodied simulation. Mind \& Language, 21(3), 434-458.

Gibbs Jr, R. W. (2011). Evaluating conceptual metaphor theory. Discourse Processes, 48(8), 529-562.

Gibbs Jr, R. W., \& Colston, H. L. (2012). Interpreting figurative meaning. Cambridge University Press.

Gibbs Jr, R. W., \& Gerrig, R. J. (1989). How context makes metaphor comprehension seem 'special'. Metaphor and Symbol, 4(3), 145-158.

Gibbs Jr, R. W., Lima, P. L. C., \& Francozo, E. (2004). Metaphor is grounded in embodied experience. Journal of pragmatics, 36(7), 1189-1210.

Gibbs, R. W, Jr., \& Matlock, T. (2008). Metaphor, imagination, and simulation: Psycholinguistic evidence. In R. W. Gibbs, Jr. (Ed.), The Cambridge handbook of metaphor and thought (pp. 161-176). New York, NY, US: Cambridge University Press. 
Gibbs, R. W. (2015). Counting Metaphors: What Does this Reveal about Language and Thought?. Cognitive Semantics, 1(2), 155-177.

Gibbs, R. W. (2017). Metaphor Wars. Cambridge University Press.

Graesser, A. C., Millis, K. K., \& Zwaan, R. A. (1997). Discourse comprehension. Annual Review of Psychology, 48(1), 163-189.

Grice, P. (1975). Logic and conversation. In P. Cole and J. Morgan (Eds.) Syntax and Semantics (pp. 41-58). New York: Academic Press.

Hauser, D. J., \& Schwarz, N. (2015). The war on prevention: Bellicose cancer metaphors hurt (some) prevention intentions. Personality and Social Psychology Bulletin, 41(1), 66-77.

Hendricks, R. K., Demjén, Z., Semino, E., \& Boroditsky, L. (2018). Emotional implications of metaphor: Consequences of metaphor framing for mindset about cancer. Metaphor \& Symbol, 33(4), 267-279.

Hitchon, J. C. (1997). The locus of metaphorical persuasion: An empirical test. Journalism \& Mass Communication Quarterly, 74(1), 55-68.

Holyoak, K. J., \& Stamenković, D. (2018). Metaphor comprehension: A critical review of theories and evidence. Psychological bulletin, 144(6), 641.

Hummel, J. E., \& Holyoak, K. J. (1997). Distributed representations of structure: A theory of analogical access and mapping. Psychological Review, 104, 427-466.

Johnson, J. T., \& Taylor, S. E. (1981). The effect of metaphor on political attitudes. Basic and Applied Social Psychology, 2(4), 305-316.

Keefer, L. A., Landau, M. J., Sullivan, D., \& Rothschild, Z. K. (2014). Embodied metaphor and abstract problem solving: Testing a metaphoric fit hypothesis in the health domain. Journal of Experimental Social Psychology, 55, 12-20. 
Keysar, B., Shen, Y., Glucksberg, S., \& Horton, W. S. (2000). Conventional language: How metaphorical is it?. Journal of Memory and Language, 43(4), 576-593.

Kintsch, W., \& Van Dijk, T. A. (1978). Toward a model of text comprehension and production. Psychological Review, 85(5), 363.

Kollias, P. \& McClelland, J. L. (2013). Context, cortex, and associations: A connectionist developmental approach to verbal analogies. Frontiers in Psychology, 4, 857.

Lakens, D. (2014). Grounding social embodiment. Social Cognition, 32, 168-183.

Lakoff, G. \& Johnson, M. (1980). Metaphors We Live By. Chicago: University of Chicago Press.

Lakoff, G., \& Johnson, M. (1999). Philosophy in the flesh: The embodied mind and its challenge to western thought (Vol. 28). New York: Basic books.

Landau, M. J., Keefer, L. A., \& Swanson, T. J. (2017). “Undoing” a Rhetorical Metaphor: Testing the Metaphor Extension Strategy. Metaphor and Symbol, 32(2), 63-83.

Landau, M. J., Sullivan, D., \& Greenberg, J. (2009). Evidence that self-relevant motives and metaphoric framing interact to influence political and social attitudes. Psychological Science, 20(11), 1421-1427.

Lee, S. W. S. \& Schwarz, N. (2014). Metaphor in judgment and decision-making. In Landau, M. E., Robinson, M. D., \& Meier, B. P. (eds.) The power of metaphor: Examining its influence on social life. American Psychological Association, 85-108.

Lee, S. W., \& Schwarz, N. (2012). Bidirectionality, mediation, and moderation of metaphorical effects: The embodiment of social suspicion and fishy smells. Journal of personality and social psychology, 103(5), 737-749. 
Leech, R., Mareschal, D., \& Cooper, R. (2008). Analogy as relational priming: A developmental and computational perspective on the origins of a complex cognitive skill. Behavioral and Brain Sciences, 31, 357-378.

Mandler, J. M. (2014). Stories, scripts, and scenes: Aspects of schema theory. Psychology Press.

McGlone, M. S. (2007). What is the explanatory value of a conceptual metaphor? Language \& Communication, 27(2), 109-126.

McGlone, M. S. (2011). Hyperbole, homunculi, and hindsight bias: An alternative evaluation of conceptual metaphor theory. Discourse Processes, 48(8), 563-574.

McGlone, M. S., \& Harding, J. L. (1998). Back (or forward?) to the future: The role of perspective in temporal language comprehension. Journal of Experimental Psychology: Learning, Memory, and Cognition, 24(5), 1211-1223.

Meier, B. P., Schnall, S., Schwarz, N., \& Bargh, J. A. (2012). Embodiment in social psychology. Topics in Cognitive Science, 4, 705-716.

Minsky, M. (1975). A framework for representing knowledge. In The Psychology of Computer Vision, P. H. Winston (Ed.), pp. 211-277. McGraw-Hill, New York.

Murphy, G. L. (1996). On metaphoric representation. Cognition, 60(2), 173-204.

Murphy, G. L. (1997). Reasons to doubt the present evidence for metaphoric representation. Cognition, 62(1), 99-108.

Nayak, N. P., \& Gibbs, R. W. (1990). Conceptual knowledge in the interpretation of idioms. Journal of Experimental Psychology: General, 119(3), 315-330.

Pérez-Sobrino, P., \& Julich, N. (2014). Let's talk music: A corpus-based account of musical motion. Metaphor and Symbol, 29(4), 298-315. 
Pinker, S. (2006). Block that metaphor. The New Republic. Retrieved Feb 14, 2019:

https://newrepublic.com/article/77730/block-metaphor-steven-pinker-whose-freedomgeorge-lakoff

Pinker, S. (2007). The stuff of thought: Language as a window into human nature. Penguin.

Read, S. J., Cesa, I. L., Jones, D. K., \& Collins, N. L. (1990). When is the federal budget like a baby? Metaphor in political rhetoric. Metaphor and Symbol, 5(3), 125-149.

Reali, F., Soriano, T., \& Rodríguez, D. (2016). How we think about depression: The role of linguistic framing. Revista Latinoamericana de Psicología, 48(2), 127-136.

Reijnierse, W. G., Burgers, C., Krennmayr, T., \& Steen, G. J. (2015). How viruses and beasts affect our opinions (or not): The role of extendedness in metaphorical framing. Metaphor and the Social World, 5(2), 245-263.

Robins, S., \& Mayer, R. E. (2000). The metaphor framing effect: Metaphorical reasoning about text-based dilemmas. Discourse Processes, 30(1), 57-86.

Rumelhart, D. E. (1975). Notes on a schema for stories. In Representation and understanding (pp. 211-236).

Schank, R. C., \& Abelson, R. P. (1977). Scripts, plans, goals, and understanding: An inquiry into human knowledge structures. Psychology Press.

Siltanen, S. A. (1981). The persuasiveness of metaphor: A replication and extension. Southern Speech Communication Journal, 47(1), 67-83.

Sopory, P., \& Dillard, J. P. (2002). The persuasive effects of metaphor: A meta-analysis. Human Communication Research, 28(3), 382-419.

Sperber, D., \& Wilson, D. (1987). Précis of relevance: Communication and cognition. Behavioral and brain sciences, 10(4), 697-710. 
Steen, G. (2008). The paradox of metaphor: Why we need a three-dimensional model of metaphor. Metaphor and Symbol, 23(4), 213-241.

Steen, G. (2010). A method for linguistic metaphor identification: From MIP to MIPVU. John Benjamins Publishing.

Steen, G. J., Reijnierse, W. G., \& Burgers, C. (2014). When do natural language metaphors influence reasoning? A follow-up study to Thibodeau and Boroditsky (2013). PloS one, 9(12), e113536.

Thibodeau, P. H. (2016). Extended metaphors are the home runs of persuasion: Don't fumble the phrase. Metaphor and Symbol, 31(2), 53-72.

Thibodeau, P. H. (2017). The function of metaphor framing, deliberate or otherwise, in a social world. Metaphor and the Social World, 7(2), 270-290.

Thibodeau, P. H., \& Boroditsky, L. (2011). Metaphors we think with: The role of metaphor in reasoning. PloS one, 6(2), e16782.

Thibodeau, P. H., \& Boroditsky, L. (2013). Natural language metaphors covertly influence reasoning. PloS one, 8(1), e52961.

Thibodeau, P. H., \& Boroditsky, L. (2015). Measuring effects of metaphor in a dynamic opinion landscape. PloS one, 10(7), e0133939.

Thibodeau, P. H., Crow, L., \& Flusberg, S. J. (2017). The metaphor police: A case study of the role of metaphor in explanation. Psychonomic bulletin \& review, 24(5), 1375-1386.

Thibodeau, P. H., \& Durgin, F. H. (2008). Productive figurative communication: Conventional metaphors facilitate the comprehension of related novel metaphors. Journal of Memory and Language, 58(2), 521-540. 
Thibodeau, P. H., \& Flusberg, S. J. (2017). Metaphorical Accounting: How Framing the Federal Budget Like a Household's Affects Voting Intentions. Cognitive science, 41, 1168-1182.

Thibodeau, P.H., Flusberg, S.J., Glick, J.J., \& Sternberg, D.A. (2013). An emergent approach to analogical inference. Connection Science, 25, 27-53.

Thibodeau, P., Winneg, A., Frantz, C., \& Flusberg, S. (2016). The mind is an ecosystem. Metaphor and the Social World, 6(2), 225-242.

Tversky, A., \& Kahneman, D. (1981). The framing of decisions and the psychology of choice. science, 211(4481), 453-458.

Vendetti, M. S., Wu, A., \& Holyoak, K. J. (2014). Far-out thinking: Generating solutions to distant analogies promotes relational thinking. Psychological Science, 25(4), 928-933.

Williams, L. E., \& Bargh, J. A. (2008). Experiencing physical warmth promotes interpersonal warmth. Science, 322(5901), 606-607.

Winter, B. (2019). Sensory linguistics: Language, Perception and Metaphor (Vol. 20). John Benjamins Publishing Company. 